\title{
PREFORMULATION STUDIES USING LACTOSE IN DEVELOPMENT OF SOLID ORAL DOSAGE FORM: A GRAPHICAL REPRESENTATION USING SeDeM METHOD
}

\author{
IMRAN TADWEE*1, SADHANA SHAHI' ${ }^{2}$, ZAHED ZAHEER' \\ 1Y. B. Chavan College of Pharmacy Rouza Buagh, Aurangabad 431001, ${ }^{2}$ Goverment College of Pharmacy Opp. Government Polytechnic \\ Osmanpura, Aurangabad 43100 (MH) India \\ Email: imran.tpharma@gmail.com
}

Received: 22 May 2017, Revised and Accepted: 22 Jul 2017

\begin{abstract}
Objective: The objective of the study is to evaluate and present lactose scientifically as an excipient of choice in formulation development of solid orals dosage form for direct compression method. Present work will establish the ability of lactose as an excipient to be the choice of candidate while developing formulation having poor flow API using direct compression process. In addition to this different type of lactose is processed using secure development method (SeDeM) in order to evaluate best suitable type of lactose amongst its different type.
\end{abstract}

Methods: Lactose anhydrous, lactose monohydrate and Lactose spray dried (SD) were employed for evaluation using SeDeM method, twelve different selected pharmacotechnical parameters were determined experimentally and were treated mathematically and expressed in the graphical representation as SeDeM diagram. Parameter index, parameter profile index and good compression index values were calculated.

Results: Good compression index was found to be $6.06,5.72,6.83$ parameter index was $0.25,0.42,0.17$ and parameter profile index found to be 6.36,6.01,7.18 for lactose anhydrous, lactose monohydrate and Lactose SD respectively.

Conclusion: This research work reveals that data obtained will be useful for the pharmaceutical industries while formulating the drug product and will reflect the scientific characteristics of this excipient as well. This will enable the availability of values obtained after performing SeDeM studies on lactose to scientific society based on the results researchers can use establised data and statistics in their pre-formulation studies to incorporate lactose with confidence and can be justified scientifically in the development formulation of the direct compression process and API having poor flow. Results indicating good direct compression characteristics of the all 3 type of lactose, and Lactose SD can be preferred amongs these 3 types.

Keywords: Lactose, SeDeM, Preformulation Studies, Galanic Method, Direct Compression, Powder flow

(C) 2017 The Authors. Published by Innovare Academic Sciences Pvt Ltd. This is an open access article under the CC BY license (http://creativecommons.org/licenses/by/4.0/) DOI: http://dx.doi.org/10.22159/ijcpr.2017v9i5.22165

\section{INTRODUCTION}

Today's regulatory environment, every aspect of formulation needs to be justified before the regulatory agency for commercialisation of the drug product, considering this compulsory aspect every pharma establishment is developing formulation scientifically which can satisfies regulatory expectations in various regulatory submissions. Now Quality by design approach has become an essential part for the formulation, while in product development report selection of excipient needs to justify. This quality checks may exists mainly considering the safety of a patient. The lactose having the quantitatively wide scope or range of usage in formulation stated in FDA's Inactive Ingredient Database, lactose is widely used as an excipient in the formulation development of solid oral dosage one can use around $735 \mathrm{mg}$ per dosage unit in case of tablet dosage form [1]. Lactose is preferred due to its characteristic of as good flow aid, diluent, dry powder inhaler carrier, lyophilization aid, capsule filler etc. Lactose is availble as anhydrous, monohydrate etc based on the requirements various grades are commercially available in the excipient industries, where anhydrous lactose is preferred for composition which contains API sensitive to moisture. Anhydrous lactose occurs as white to off-white crystalline particles or powder, which contain anhydrous b-lactose and anhydrous a-lactose. Anhydrous lactose typically contains 70-80\% anhydrous b-lactose and 20-30\% anhydrous a-lactose Adverse reactions to lactose are largely due to lactose intolerance, which occurs in individuals with a deficiency of the intestinal enzyme lactase, and is associated with oral ingestion of amounts well over those found in solid dosage forms [2]. Lactose has molecular formula $\mathrm{C} 12 \mathrm{H} 22011$ and melting point is $201-202^{\circ} \mathrm{C}[3]$.

\section{SeDeM method}

SeDeM Method is used in the pre-formulation studies which emphasis always on the physical properties of drug substances related to its suitability in the direct compression process. While in this article we are highlighting the advantage of lactose with good physical properties for its application or usage in the formulation with its statistics obtained after performing 12 test of SeDeM method, SeDeM is a reliable method for pre-formulation studies and as a quality control tool for studying the batch-to-batch reproducibility of API and Excipients. Furthermore, it establishes the notion that blending poorly compressible drugs with suitable ingredients followed by SeDeM studies could be used as a method for identifying best excipient and calculating the maximum amount of excipient required for direct compression of API which is having poor flow [4].

The SeDeM method is based on the experimental study and quantitative determination of the characterization parameters of powdered substances that provide the necessary information about the ability of a substance to be used for direct-compression technology. The considered parameters are as follows: bulk density (Da), tapped density (Dc), interparticle porosity (Ie), Carr index (IC), cohesion index (Icd), Hausner ratio (IH), angle of repose (a), flowability (tn), loss on drying (\%LoD), hygroscopicity $(\% \mathrm{H})$, particle size (\%Pf) and homogeneity index (Iq). These parameters were determined by validated experimental methods and processed for fitting into SeDeM diagram method and analyzed for studying the suitability of the powder for direct compression. Hence, SeDeM diagram method could be described as a mathematical and graphical representation of powder characteristic parameters for studying direct compression suitability of various active and inactive ingredients [5-7]. The details 12 tests of SeDeM and their units, equations factors are explained in table 1 and fig. 1

\section{MATERIALS AND METHODS}

Lactose unhydrous, Lactose monohydrate and Lactose SD excipient is 
obtained from Wockhardt Pharmaceuticals Aurangabad as a gift sample pharmacopoeia methodologies are used to calculate parameters of SeDeM, as well as a common strategy used in pharmaceutical technology development, is applied for constructing the SeDeM Diagram. The methods used for each test are described below [6].

\section{Bulk density (Da)}

Bulk density was calculated in accordance with the method described in section 2.9.15 of European Pharmacopoeia [8]. The total volume in bulk density measurements included particle volume, inter-particle void volume and internal pore volume.

\section{Tapped density (Dc)}

Tapped density was calculated in accordance with the method described in Section 2.9.15 of European Pharmacopoeia [9]. It was determined by applying a controlled packing force to the sample and included the interstitial volume and pore volume in its calculations. Graduated cylinder (Voluminometer) was employed for density measurements and the volume taken was the value obtained after 2500 strokes using a settling apparatus.

\section{Inter-particle porosity (Ie)}

The inter-particle porosity of the drug powder was calculated by the following equation

$\mathrm{Ie}=\mathrm{Dc}-\mathrm{Da} / \mathrm{Dc} \mathrm{X} \mathrm{Da}$

\section{Carr index (IC \%)}

It was computed from Da and Dc using the following equation

$$
\mathrm{IC}=(\mathrm{Dc}-\mathrm{Da} / \mathrm{Dc}) \times 100
$$

\section{Cohesion index (Icd)}

The cohesion index was determined by directly compressing the drug powder under study using an eccentric press. The hardness $(\mathrm{N})$ of the obtained tablets was determined and the mean hardness was calculated.

\section{Hausner ratio (IH)}

This was calculated from Da and Dc using the following expression $\mathrm{IH}=\mathrm{Dc} / \mathrm{Da}$.

\section{Angle of repose ( $\alpha)$}

It is the three-dimensional angle formed by cone like a pile of the material during the determination. The angle of the cone formed was calculated after the product was passed through a funnel with the following dimensions: funnel height $9.5 \mathrm{~cm}$, an upper diameter of spout $7.2 \mathrm{~cm}$, internal diameter at the bottom, narrow end of spout $1.8 \mathrm{~cm}$. The funnel was placed on a support at $20 \mathrm{~cm}$ from table surface, centred over a millimetre-grid sheet on which two intersecting lines were drawn, crossing at the Centre. The narrow end of the funnel spout was plugged and the funnel was filled with the product under study until it was flushed with the top end of the spout when smoothed with a spatula.

Thereafter, the plug was removed and the powder was allowed to fall onto the millimetre sheet. The radius of the cone base was measured with a slide caliper and the mean value ( $r$ ) was calculated. Additionally, the cone height $(\mathrm{h})$ was measured and the angle tangent value $(\alpha)$ of the cone was calculated employing the following equation, scale of flow ability mentioned in table 2 .

$\tan \alpha=\mathrm{h} / \mathrm{r}$

\section{Flow ability (tn)}

The flow rate described herein as flow ability was determined in accordance with the method described in Section 2.9.16-2 of European Pharmacopoeia [9] as the time for a fixed amount of powder to flow through a glass tunnel with $0.85 \mathrm{~cm}$ orifice diameter. It was expressed in seconds and tenths of a second per 100 grams of sample, with the mean value of three determinations always being taken.

\section{Loss on drying (\%HR)}

This is determined by the loss on-drying test carried out in accordance with General Method 2.2.32 in European Pharmacopoeia [8]. Lactose anhydrous was dried in a convection oven at $105^{\circ} \mathrm{C} \pm 2{ }^{\circ} \mathrm{C}$ until a constant weight is obtained.

\section{Hygroscopicity $(\% \mathrm{H})$}

The hygroscopicity of a powder is its equilibrium moisture content after being exposed to air humidity under given conditions. It was determined by calculating the increase in sample weight after being kept in a humidifier at an ambient relative humidity of $76 \% \pm 2 \%$ and a temperature of $22^{\circ} \mathrm{C} \pm 2{ }^{\circ} \mathrm{C}$ for $24 \mathrm{~h}$.

\section{Percentage of particles measuring $<50 \mu(\% \mathrm{Pf})$}

Particle size was determined by means of the sieve test in accordance with the General method 2.9.12 of European Pharmacopoeia [9] and was expressed as the $\%$ of particles that pass through a $0.05 \mathrm{~mm}$ (ASTM\# 270) sieve when vibrated for $10 \mathrm{~min}$ at speed 10 using a sieve vibrator.

\section{Homogeneity index $(\mathrm{I} \theta)$}

The method for determination of I $\theta$ was based on General method 2.9.12 of European Pharmacopoeia for determining particle size by means of the sieve test [9][10]. The grain size of a $100 \mathrm{~g}$ sample was determined by submitting a sieve stack to vibration for $10 \mathrm{~min}$ at the speed $10 \mathrm{using}$ a sieve vibrator. Sieve sizes used were: $0.355,0.212,0.100$ and $0.05 \mathrm{~mm}$. (ASTM\# 45, \#70, \#140 \#270 respectively) the percentage of product retained in each sieve and the quantity that passes through the $0.05 \mathrm{~mm}$ sieve were calculated. The percentage of fine particles $(<50 \mu)$ determined previously in a separate operation was considered. The following equation was then applied to the data obtained:

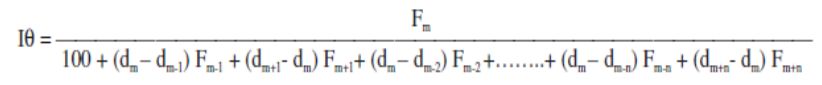

Where,

$\mathrm{I} \theta=$ relative homogeneity index; $\mathrm{Fm}=$ percentage of particles in the majority range;

$\mathrm{Fm}-1=$ percentage of particles in the range immediately below the majority range;

$\mathrm{Fm}+1=$ percentage of particles in the range immediately above the majority range;

$\mathrm{n}=$ order number of the fraction under study, within a series, with respect to the majority fraction;

$\mathrm{dm}=$ the mean diameter of particles in the majority fraction;

$\mathrm{dm}-1=$ the mean diameter of particles in the fraction of the range immediately below the majority range;

$\mathrm{dm}+1=$ mean diameter of the particles in the fraction of the range immediately above the majority range.

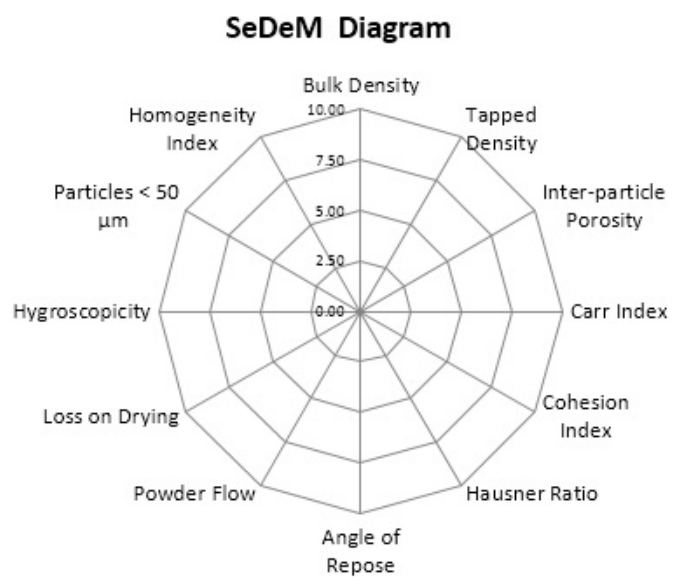

Fig. 1: 12 Tests of SeDeM diagram 
Table 1: Parameters and factors for radius calculation used in SeDeM diagram method

\begin{tabular}{|c|c|c|c|c|c|}
\hline Parameter (symbol) & Unit & Equation & Limit Value & Radius & Factor Applied \\
\hline Bulk Density (Da) & $\mathrm{gm} / \mathrm{ml}$ & $\mathrm{Da}=\mathrm{P} / \mathrm{Va}$ & $0-1$ & $0-10$ & $10 \mathrm{v}$ \\
\hline Tapped Density (Dc) & $\mathrm{gm} / \mathrm{ml}$ & $\mathrm{Dc}=\mathrm{P} / \mathrm{Vc}$ & $0-1$ & $0-10$ & $10 v$ \\
\hline Interparticle porosity (Ie) & - & $\mathrm{Ie}=\mathrm{DC}-\mathrm{Da} / \mathrm{Dc} \times \mathrm{Da}$ & $0-1.2$ & $0-10$ & $10 \mathrm{v} / 1.2$ \\
\hline Carr index (Icd) & $\%$ & $\mathrm{IC}=(\mathrm{Dc}-\mathrm{Da} / \mathrm{Dc})$ & $0-50$ & $0-10$ & $10-(\mathrm{v} / 5)$ \\
\hline Cohesion index (IC) & $\mathrm{N}$ & Experimental & $0-200$ & $0-10$ & $\mathrm{v} / 20$ \\
\hline Hausner Ration (IH) & - & $\mathrm{IH}=\mathrm{Dc} / \mathrm{Da}$ & $3-0$ & $0-10$ & $10-(10 v / 3)$ \\
\hline Angle of repose $(\alpha)$ & - & $\mathrm{A}=\tan ^{-1} \mathrm{~h} / \mathrm{r}$ & $50-0$ & $0-10$ & $10-(\mathrm{v} / 5)$ \\
\hline Flowability $\left(\mathrm{t}^{\mathrm{n}}\right)$ & S & Experimental & $20-0$ & $0-10$ & $10-(\mathrm{v} / 2)$ \\
\hline Loss on Drying (\% LOD) & $\%$ & Experimental & $10-0$ & $0-10$ & $10-\mathrm{v}$ \\
\hline Hygroscopicity $(\% \mathrm{H})$ & $\%$ & Experimental & $20-0$ & $0-10$ & $10-(\mathrm{v} / 2)$ \\
\hline Particles <50 m (\%Pf) & $\%$ & Experimental & $50-0$ & $0-10$ & $10-(\mathrm{v} / 5)$ \\
\hline Homogeneity index (IӨ) & - & Eq. (1) & $0-0.02$ & $0-10$ & $500 \mathrm{v}$ \\
\hline
\end{tabular}

\section{Acceptable limits}

To establish powder suitability for direct compression, given mathematical indices equation 1, 2 and 3 are calculated based on SeDeM diagram.

$$
\text { A] Parameter index (IP) }=\frac{n^{\circ} \mathrm{P} \geq 5}{n^{\circ} \mathrm{Pt}}
$$

B] Parameter index (IP) $=\frac{\text { No of parameters having } r \geq 5}{\text { Total No of Parameters }}$

\section{Where}

No. $p \geq 5$ : Indicates the number of parameters whose value is equal to or higher than 5

No. Pt: Indicates the total number of parameters studied

Acceptable limit is when IE 0.5 Parameter profile index (IPP) $=$ Mean $r$ of all the parameters Acceptable limit is when IPP $\geq 5$

C] Good compression index (GCI) = IPP x f...

Where, $\mathrm{f}$ is a reliability factor and $\mathrm{f}=$ polygon area/circle area
Acceptable limit is when IPP $\geq 5$

All above described 12 test of SeDeM and evaluation of acceptable limits were calculated for all 3 types of lactose 1) Lactose unhydrous, 2) Lactose Monohydrate and 3) Lactose SD

\section{RESULTS AND DISCUSSION}

The experiments were performed in duplicate to ensure suitability of method and statistically significant results, followed by calculating the mean value of the parameters. As described in table 1 , conversion factors could be applied to the respective parametric values to obtain the radius (r). Experimental value the mean of experimental values (V) and the respective mean of radius values (R) of different flow parameters were obtained of lactose shown in the table 3. Also, the type of flow can be compared with the limits given in USP shown in table 2 scale of flowability. These calculated radius values were graphically expressed on a regular circle graph (histogram) by plotting the radius values. The SeDeM diagrams were then drawn by connecting the radius values with linear segments. The void age fractions of tapped and loosely packed powder beds have been known to be related semi empirically to the size distribution, shape, and density of the constituent particles[7,10]. Result obtained is tabulated in table 3 and 4.

Table 2: Scale of flowability as per USP

\begin{tabular}{llll}
\hline Flow characters & Carr index & Hausner ration & Angle of repose \\
\hline Excellent & $\leq 10$ & $1.00-1.11$ & $25-30$ \\
Good & $11-15$ & $1.12-1.18$ & $31-35$ \\
Fair (Aid not needed) & $16-20$ & $1.19-1.25$ & $36-40$ \\
Passable (May hang up) & $21-25$ & $1.26-1.34$ & $41-45$ \\
Poor (Must agitate/vibrate) & $26-31$ & $1.35-1.45$ & $46-55$ \\
Very Poor & $32-37$ & $1.46-1.59$ & $56-65$ \\
Very Very Poor & $>38$ & $>1.60$ & $>66$ \\
\hline
\end{tabular}

Table 3: Experimental and radius values

\begin{tabular}{|c|c|c|c|c|c|c|c|c|c|}
\hline \multirow{2}{*}{$\begin{array}{l}\text { S. } \\
\text { No. }\end{array}$} & \multirow{2}{*}{$\begin{array}{l}\text { Parameter } \\
\text { (Symbol) }\end{array}$} & \multirow{2}{*}{$\begin{array}{l}\text { Acceptab } \\
\text { le value } \\
\text { limit }\end{array}$} & \multirow{2}{*}{$\begin{array}{l}\text { Acceptable } \\
\text { radius } \\
\text { limit }\end{array}$} & \multicolumn{3}{|c|}{ Value obtained (V) } & \multicolumn{3}{|c|}{ Corresponding radius (R) } \\
\hline & & & & $\begin{array}{l}\text { Lactose } \\
\text { anhydrous }\end{array}$ & $\begin{array}{l}\text { Lactose } \\
\text { monohydrate }\end{array}$ & $\begin{array}{l}\text { Lactose } \\
\text { SD }\end{array}$ & $\begin{array}{l}\text { Lactose } \\
\text { anhydrous }\end{array}$ & $\begin{array}{l}\text { Lactose } \\
\text { monohydrate }\end{array}$ & $\begin{array}{l}\text { Lactose } \\
\text { SD }\end{array}$ \\
\hline 1 & Bulk Density (Da) & $0-1$ & $0-10$ & 0.65 & 0.685 & 0.698 & 6.51 & 6.85 & 6.98 \\
\hline 2 & Tapped Density (Dc) & $0-1$ & $0-10$ & 0.88 & 0.859 & 0.891 & 8.77 & 8.59 & 8.91 \\
\hline 3 & $\begin{array}{l}\text { Interparticle porosity } \\
\text { (Ie) }\end{array}$ & $0-1.2$ & $0-10$ & 0.40 & 0.30 & 0.31 & 3.30 & 2.46 & 2.59 \\
\hline 4 & Carr index (Icd) & $0-50$ & $0-10$ & 25.77 & 20.26 & 21.66 & 5.15 & 4.05 & 4.33 \\
\hline 5 & Cohesion index (IC) & $0-200$ & $0-10$ & 111.00 & 91.00 & 148.00 & 5.55 & 4.55 & 7.40 \\
\hline 6 & Hausner Ration (IH) & $3-0$ & $0-10$ & 1.35 & 1.25 & 1.28 & 8.26 & 8.73 & 8.62 \\
\hline 7 & Angle of repose $(\alpha)$ & $50-0$ & $0-10$ & 26.00 & 39.00 & 21.00 & 4.80 & 2.20 & 5.80 \\
\hline 8 & Flowability (tn) & $20-0$ & $0-10$ & 9.00 & 15.00 & 7.00 & 5.50 & 2.50 & 6.50 \\
\hline 9 & Loss on Drying (\% LOD) & $10-0$ & $0-10$ & 0.77 & 2.25 & 1.01 & 9.23 & 7.75 & 8.99 \\
\hline 10 & Hygroscopicity $(\% \mathrm{H})$ & $20-0$ & $0-10$ & 0.50 & 0.75 & 1.57 & 9.75 & 9.63 & 9.22 \\
\hline 11 & Particles < 50 m (\%Pf) & $50-0$ & $0-10$ & 15.00 & 21.00 & 11.00 & 7.00 & 5.80 & 7.80 \\
\hline 12 & Homogeneity index (IӨ) & $0-0.02$ & $0-10$ & 0.01 & 0.02 & 0.02 & 2.50 & 9.00 & 9.00 \\
\hline
\end{tabular}

*Average value of 2 readings ( $\mathrm{N}=2$ ) 
Table 4: Acceptance limit values

\begin{tabular}{llll}
\hline S. No. & Parameter & Lactose unhydrous & Lactose monohydrate \\
\hline 1 & Parametric index (IP) & 0.5 & 0.5 \\
2 & Parametric profile index (IPP) & 6.36 & 6.01 \\
3 & Good compression index (GCI) & 6.06 & 5.72 \\
\hline
\end{tabular}

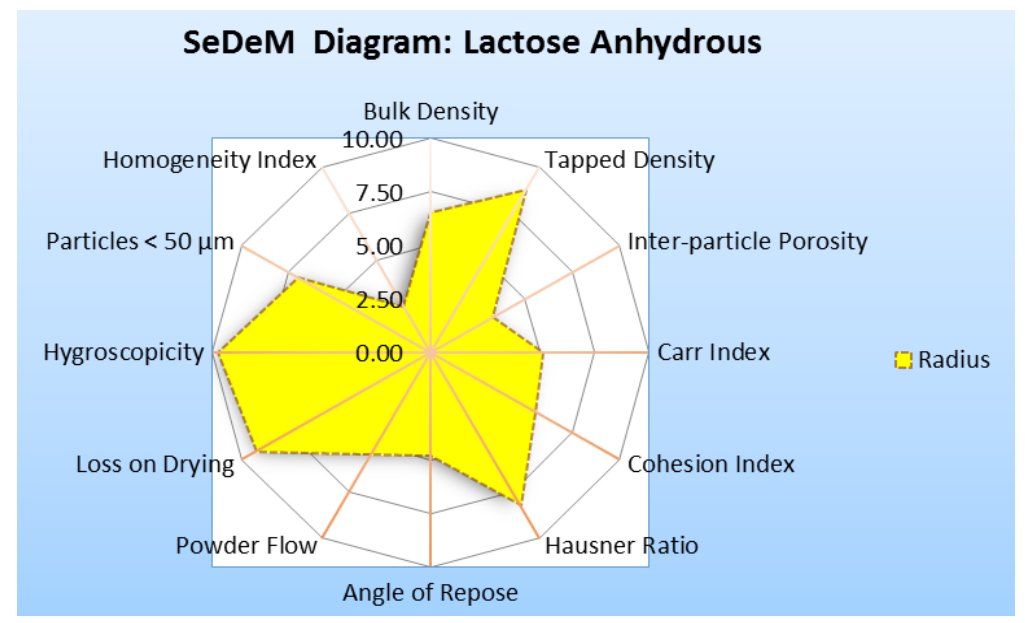

Fig. 2: SeDeM diagram of lactose anhydrous

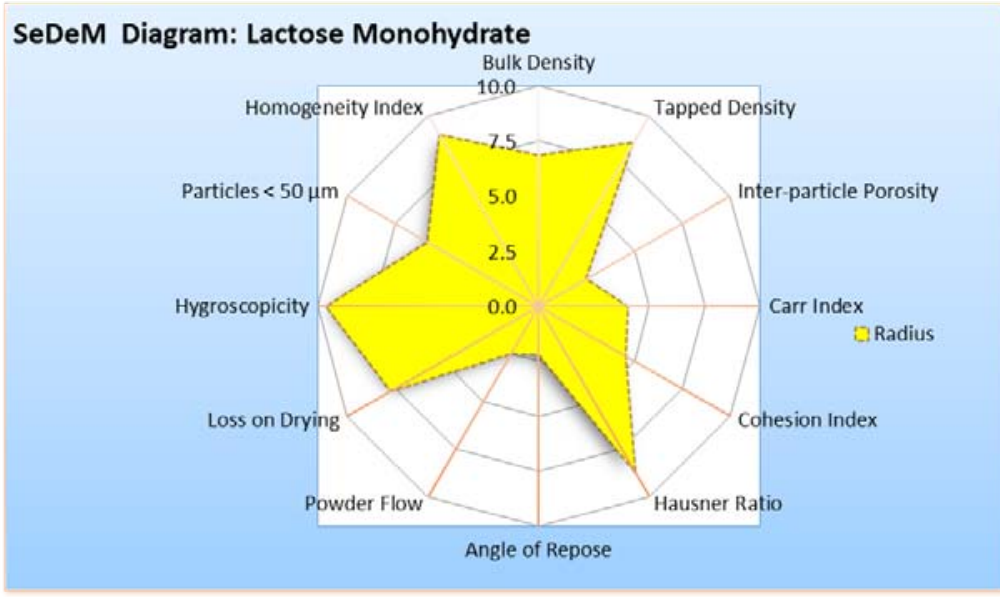

Fig. 2: SeDeM diagram of lactose monohydrate

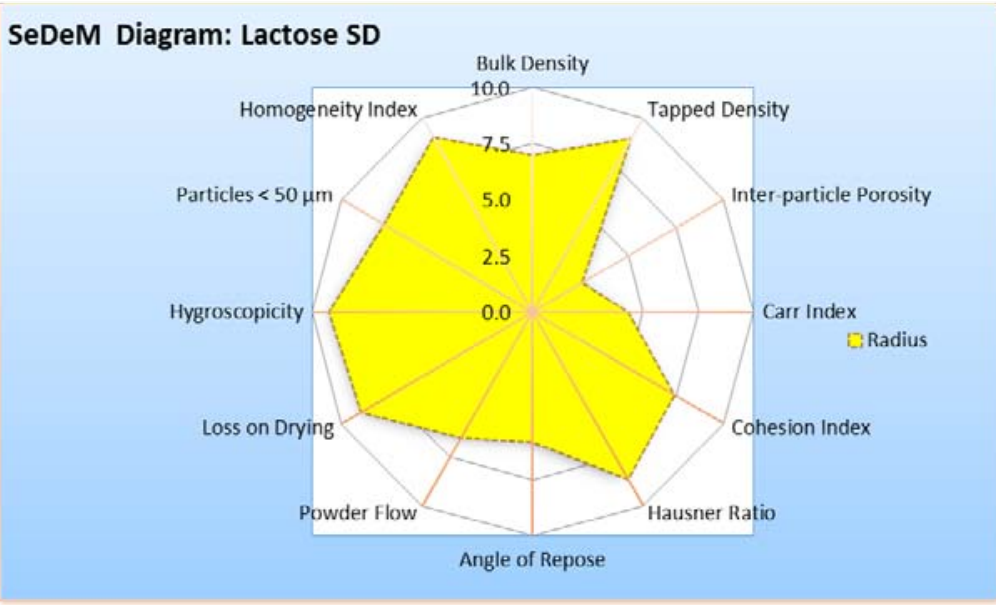

Fig. 2: SeDeM diagram of lactose SD 


\section{CONCLUSION}

SeDeM parameters studied on different types of lactose, study results indicate all types of lactose are a suitable candidate for direct compression as all are having IPP value more than 5 . The values of the Parametric index (IP), Parametric profile index (IPP) and Good compression index (GCI) shows that Lactose SD can be a preferred choice of excipient than other types of lacotse excipient. All above 3 types of lactose can be incorporated with API having poor flow. Values applied in SeDeM diagram which reveals that 10 of 12 parameters having radius equals to or more than 5 which indicates that L: actose SD is the choice of excipient for masking poor flow property of drug substances. Based on the result obtained Lactose $\mathrm{SD}$ is recommended to be used in the formulation. In line of these observations SeDeM diagram method could be seen as a useful preformulation tool for galenic characterization excipients with respect to their suitability for direct compression, also establishes a reliable method for pre-formulation studies, this method also enables to provide the justification of use of excipient.

\section{ACKNOWLEDGMENT}

We thank to principle Government College of Pharmacy and Y. B. Chavan College of Pharmacy Aurangabad for support and institutional facility.

\section{CONFLICT OF INTERESTS}

All Authors have none to declare

\section{REFERENCES}

1. USFDA's Inactive ingredient database search for Anhydrous Lactose. Available from: https://www.accessdata.fda.gov/ scripts/cder/iig/getiigWEB.cfm. [Last accessed on 15th May 2017].
2. Raymond C Rowe, Paul J Sheskey, Marian E Quinn. Handbook of phrmaceutical excipient. Sixth edition; 2009. p. 359-76.

3. National Center for Biotechnology Information. PubChem Compound Database; CID $=440995$. Available from: https://pubchem.ncbi.nlm.nih.gov/compound/440995. [Last accessed 14 May 2017].

4. Montserrat M, Pilar P, Josep MS, Manel R, Roser F, Encarna G, et al. A new expert system (SeDeM Diagram) for control btach powder formulation and preformulation drug product. Eur J Pharm Biopharm 2006;64:351-9.

5. Montserrat M, Pilar P, Josep MS, Manel R, Roser F, Encarna G, et al. Application of the SeDeM diagram and a new mathematical equation in the design of direct compression tablet formulation. Eur J Pharm Biopharm 2008;69:1029-39.

6. Josep M, Sune Negre. SeDeM diagram: a new expert system for the formulation of drugs in solid form. Expert system for human, material and atomization (Intech); 2011. p. 17-34.

7. Inderbir Singh, Pradeep Kumar. Preformulation studies for direct compression suitability of cefuroxime axetil and paracetamol: a graphical representation using sedem diagram. Acta Pol Pharm 2012;69:87-93.

8. European Pharmacopoeia. 5, 2.2.32. Council of Europe, Strasbourg (France); 2005.

9. European Pharmacopoeia, 5, 2.9.38. Council of Europe, Strasbourg (France); 2005.

10. Hoffmann AC, Finkers HJ. Powder Technol 1995;82:14-59.

\section{How to cite this article}

- Imran Tadwee, Sadhana Shahi, Zahed Zaheer. Preformulation studies using lactose in development of solid oral dosage form: a graphical representation using SeDeM method. Int J Curr Pharm Res 2017;9(5):168-172. 